\title{
A Descriptive Review of Epidemiology of COVID-19 in Smokers
}

\author{
Rupalakshmi Vijayan1, Shavy Nagpal2*, Swostik Pradhananga1, Anoopa Mathew1, \\ Sindhu Thevuthasan', Sirisha Gara1, Pavani Chitamanni' ${ }^{1}$, Syed Adeel Hassan', Miguel Diaz1 \\ ${ }^{1}$ Larkin Community Hospital, Miami, Florida, USA \\ ${ }^{2}$ The Clinic @Joe’s, The Research Institute of St. Joe's, Hamilton, Canada \\ Email: rupavijayan92@gmail.com, *shav.nagpal@gmail.com
}

How to cite this paper: Vijayan, R., Nagpal, S., Pradhananga, S., Mathew, A., Thevuthasan, S., Gara, S., Chitamanni, P., Hassan, S.A. and Diaz, M. (2021) A Descriptive Review of Epidemiology of COVID-19 in Smokers. Journal of Biosciences and Medicines, 9, 154-165.

https://doi.org/10.4236/jbm.2021.99014

Received: August 8, 2021

Accepted: September 26, 2021

Published: September 29, 2021

Copyright $\odot 2021$ by author(s) and Scientific Research Publishing Inc. This work is licensed under the Creative Commons Attribution International License (CC BY 4.0).

http://creativecommons.org/licenses/by/4.0/

\begin{abstract}
Background: COVID-19 is an ongoing global pandemic with paucity of the understanding of the natural history of the disease and how it affects smokers. We aim to study the outcomes of COVID-19 in smokers in this descriptive review. Coronavirus disease 2019 caused by severe acute respiratory syndrome Coronavirus 2, gains entry to bronchial epithelial cells by attachment of the viral spike protein to Angiotensin-Converting Enzyme-2 (ACE-2) receptors. Accordingly, this review aims to understand the associated risk and worsen disease in relation to smoking and explore conflicting information regarding nicotine as well as its potential protective role. Methods: We conducted a nonsystematic review of databases with search engines such as, PubMed, Google Scholar with keywords like "COVID-19," "SARS-CoV-2," "novel coronavirus," smoking," "smokers," "nicotine." It included English articles related to the epidemiology of COVID-19 in adult smokers, containing systematic reviews, meta-analysis, prospective and retrospective cohort studies, cross-sectional studies, case series, and case reports based on the relevance of titles and abstracts to the topic. Results: A total of 33 articles were reviewed. Smokers were 1.4 times more likely to have severe COVID-19 ( $R R=1.4,95 \%$ CI: $0.98-2.00$ ), and 2.4 times more likely to require an ICU admission $(\mathrm{RR}=2.4$, CI: 1.43 4.04) when compared to non-smokers $(\mathrm{n}=926)$. Current smokers were less likely to experience an adverse outcome (OR: 0.42, 95\% CI: 0.24 - 0.74), compared to former smokers. $22 \%$ of current smokers and $46 \%$ of former smokers had more severe complications compared to non-smokers with COVID-19 infection. Current smokers had a case fatality rate of $38.5 \%(n=1790)$. They had higher odds of mortality compared to non-smokers $(\mathrm{OR}=1.25)$, especially males $>65$ years age $(\mathrm{OR}=2.51)$. Tobacco smoke upregulates inflammatory cytokines like TNF- $\alpha$, IL- $1 \beta$, and neutrophils by activating NF-k. Hence, it leads to increased epithelial cell permeability, mucus production, and im-
\end{abstract}


paired mucociliary clearance. The pro-inflammatory action of tobacco smoke impairs the basal laminar cells and causes endothelial dysfunction of the BBB and blood vessels, which leads to neurological, cerebrovascular, and thrombotic complications. Conclusion: Smoking is associated with worse outcomes and mortality in COVID-19. Public education about smoking cessation should be implemented along with standard guidelines to prevent disease progression in this susceptible population.

\section{Keywords}

COVID-19, Coronavirus, Smoking, Mortality, Public Health

\section{Introduction}

With the emergence of the COVID-19 global pandemic, the scientific community has undertaken efforts to understand the epidemiology of the disease in order to mitigate adverse outcomes and the worldwide crisis. Smoking has increased risks for many respiratory infections and may accelerate the progress of the disease in those infected [1] [2] (Figure 1).

\subsection{Epidemiology of Smoking}

Smoking is a well-established risk factor for severe exacerbations or disease course in many respiratory infections, and may predispose to COVID-19 infection or worsen disease progression. With influenza and the MERS outbreak, patients who were smokers had an increased risk twice than that of non-smokers and were associated with higher mortality rates [3] [4], so it is necessary to investigate the relation to COVID-19. Current smokers also had a higher case fatality rate of $38.5 \%$ and were 1.45 times more likely to have morbid outcomes compared to their non-smoking counterparts [4]. As a modifiable risk factor,

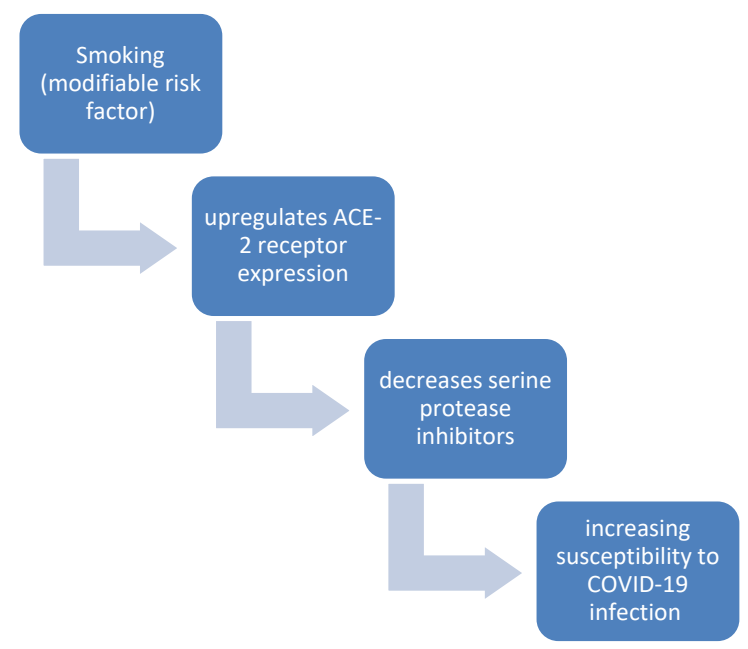

Figure 1. Smoking and COVID-19. 
smoking is a very crucial consideration in COVID-19, so this literature review aims to understand the risk of COVID-19 with smoking, the relation of smoking to the progression of the disease and clinical course, and explore debating information regarding nicotine as well as its potential protective role due to competition of nicotinic acetylcholine receptor with SARS-CoV-2 binding sites.

\subsection{Pathophysiology of Smoking in COVID}

The disease is caused by the novel coronavirus SARS-CoV-2, which gains entry to the bronchial epithelial cells and pneumocytes by binding the viral spike protein to ACE-2 receptors. The TMPRSS2 cleaves the ACE-2, thus promoting viral uptake by the host cells [3] [4]. We conducted a descriptive review to summarize concurrent studies and relate the impact of smoking on the severity, morbidity, and mortality of admitted COVID-19 patients. This review aims to understand the associated risk and worsening of disease in relation to smoking and explore conflicting information regarding nicotine as well as its potential protective role. We conducted a descriptive review to summarize concurrent studies and relate the impact of smoking on the severity, morbidity, and mortality of admitted COVID-19 patients [5] [6] [7].

The pro-inflammatory action of tobacco smoke impairs the basal laminar cells and causes endothelial dysfunction of the BBB and blood vessels, which leads to neurological, cerebrovascular, and thrombotic complications [1]. 7.63\% (95\% CI $3.83 \%-12.43 \%$ ) has been related to smoking in hospitalized patients with COVID19 [7]. Nicotine reduces the macrophage response and thereby increases the risk of tuberculosis by 2 times and legionella, pneumococcal and mycoplasma infection by 3 - 5 times. There have been studies showing the association of FEV1 with increased ACE gene expression.

Higher mortality in smokers has been seen as compared to non-smokers $(1.25$ (95\% CI 1.12 - 1.40) i [8] $\mathrm{n}=3027$, male: OR $=1.76,95 \%$ CI $(1.41,2.18), \mathrm{p}<$ 0.00001 age over 65 years old: current smoking: $\mathrm{OR}=2.51,95 \% \mathrm{CI}(1.39,3.32)$, $\mathrm{p}=0.0006$ ) [9]. Permeability of $\mathrm{BBB}$ alteration and modification of $\mathrm{Na}^{+} \mathrm{K}^{+} 2 \mathrm{Cl}^{-}$ cotransporter causes neurological complications in smokers. In 214 patients in a study, of the smoker's studies, $36.5 \%$ showed neurological symptoms and $18.7 \%$ were admitted in ICU [4] [9] (Figure 2).

33 Articles reviewed

Smokers:

a. 1.4 times severity

( $\mathrm{RR}=1.4$ 95\% Cl: 0.98

2.00)

b. 2.4 times ICU $(\mathrm{RR}=$

$2.4 \mathrm{Cl}: 1.43-4.04)$

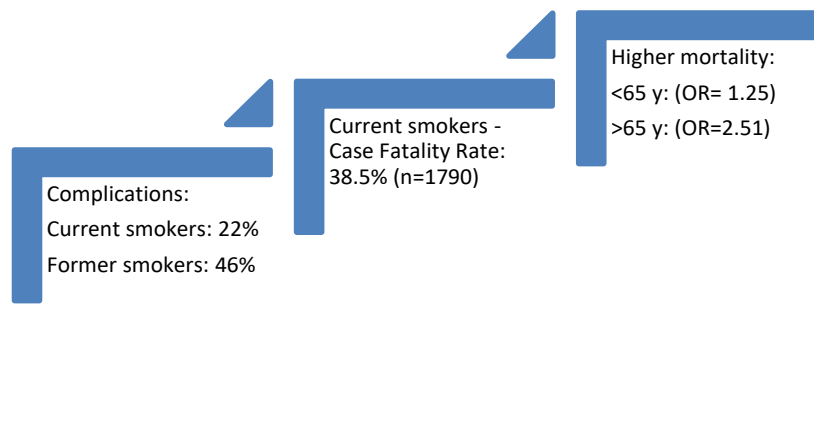

Figure 2. Results highlights: smoking and COVID-19. 


\subsection{Comparison between Current, Ex-Smokers, Non-Smokers}

Jackson, S.E., et al. study with 53,002 adults in the UK showed the following values: while comparing with non-smokers $(0.26 \%$ (95\% CI $0.21 \%$ to $0.33 \%)$ ), the prevalence among current smokers with confirmed COVID-19 was higher $(0.56 \%$ $(0.41 \%$ to $0.75 \%))$ but not in the ex-smokers $(0.19 \%(0.13 \%$ to $0.28 \%))$. They found that the associations before (current: $\mathrm{OR}=2.14(1.49-3.08)$; ex-smokers: $\mathrm{OR}=0.73(0.47-1.14)$ ) and after (current: $\mathrm{OR}=1.79(1.22-2.62)$; ex-smokers: $\mathrm{OR}=0.85(0.54-1.33))$ were similar after adjustment. For current smokers, this was moderated by socio-economic position, with higher rates only seen in those without post-16 qualifications ( $\mathrm{OR}=3.53(2.04-6.10)$ ). After including suspected cases, prevalence was higher among current smokers $(11.2 \%(10.6 \%$ to $11.9 \%), \mathrm{OR}=1.11(1.03-1.20))$ and ex-smokers $(10.9 \%(10.4 \%$ to $11.5 \%), \mathrm{OR}=$ $1.07(1.01-1.15))$ than never smokers $(10.2 \%(9.9 \%$ to $10.6 \%))$, but remained higher only among ex-smokers after adjustment $(\mathrm{OR}=1.21(1.13-1.29))$. Current and ex-smokers had higher odds than never smokers of reporting significant stress about becoming seriously ill from COVID-19 (current: OR $=1.34$ (1.27 - 1.43); ex-smokers: OR = $1.22(1.16-1.28))$. Adherence to recommendations to prevent spread of COVID-19 was high ( $96.3 \%$ (96.1\% to $96.4 \%)$ ), but lower among current than never smokers (OR $=0.70$ (0.62 - 0.78)) [10].

Farsalinos, K., et al. study showed the following values: "Among 6515 patients, the pooled prevalence of current smoking was 6.8\% (95\% confidence interval (CI): $4.8 \%-9.1 \%$ ). The gender-adjusted POR was 0.20 (95\% CI: $0.16-0.25, \mathrm{p}<$ $0.001)$, and the gender and age-adjusted POR was 0.24 (95\% CI: $0.19-0.30, \mathrm{p}<$ 0.001). Current smokers were more likely to have an adverse outcome compared with non-current smokers (Odds Ratio (OR): 1.53, 95\% CI: $1.06-2.20, \mathrm{p}=0.022$ ) but less likely compared with former smokers (OR: 0.42, 95\% CI: $0.27-0.74, \mathrm{p}=$ $0.003)$. When pre-publications were added $(n=10,631)$, the gender-adjusted POR was 0.27 (95\% CI: $0.19-0.38, \mathrm{p}<0.001)$ and the gender and age-adjusted POR was 0.34 (95\% CI: $0.24-0.48, \mathrm{p}<0.001)$ [11].

Umnuaypornlert, A. et al. study showed the following values: "A total of 1248 studies were retrieved and reviewed. A total of 40 studies were finally included for meta-analysis. Both current smoking and former smoking significantly increase the risk of disease severity $(\mathrm{OR}=1.58 ; 95 \% \mathrm{CI}: 1.16-2.15, \mathrm{p}=0.004$; and $\mathrm{OR}=2.48$; 95\% CI: $1.64-3.77, \mathrm{p}<0.001$; respectively) with moderate appearance of heterogeneity. Similarly, current smoking and former smoking also significantly increase the risk of death $(\mathrm{OR}=1.35$; 95\% CI: $1.12-1.62, \mathrm{p}=0.002$; and $\mathrm{OR}=2.58$; 95\% CI: $2.15-3.09, \mathrm{p}<0.001$; respectively) with moderate appearance of heterogeneity. There was no evidence of publication bias, which was tested by the funnel plot, Begg's test and Egger's test" [12].

\subsection{Smoking, FEV1, and COPD Association in Respiratory Diseases}

Chronic Obstructive pulmonary disease is characterized by structural and functional changes in the lungs that is caused by long term inhalation of substances. COPD involves persistent inflammation and airway remodeling that leads to 
airway obstruction mediated by cytokines and other inflammatory mediators. Cigarette smoke has several toxic particles and chemical substances that leads to persistent chronic inflammation and airway damage that persists even after smoking cessation [12]. Many markers of oxidative stress and reactive oxygen species have been implicated in the pathogenesis of COPD like lipid and hydrogen peroxides that are increased in the respiratory tract and blood of COPD patients.

Healthy lungs have antioxidants that act as a defense and maintain the balance between oxidants and antioxidants. Disruption of balance causes increased airway inflammation, increased airway mucus production and inactivation of antiproteases [13]. Cigarette smoke induced mitochondria autophagy that initiates necroptosis. Necroptosis is a new mechanism of cell death that causes more inflammatory damage unexplained by apoptosis. This also contributes to the complex mechanism of cigarette smoke induced COPD damage [14] while SARS COV can affect individuals of any age, this is mostly associated with people over age $>55$ and with significant comorbidities like COPD [15].

COPD should be diagnosed by a board certified physician or a decrease in FEV $1<70 \%$ according to the spirometry guidelines [16] smoking and COPD both are associated with increased expression of ACE 2 receptors which is supposed to be the entry mechanism of COVID-19. St. Paul's Hospital conducted a cohort study in patients with chronic nodules have undergone bronchoscopy followed by cough and lymphadenopathy.

There was an increased association between COPD and smoking with ACE 2 expression. There was an inverse relationship between ACE 2 expression and FEV\% suggesting a dose dependent response. According to Cornell and BCCA cohorts there was an increased ACE 2 expression in smokers and non-smokers [17].

\subsection{Nicotine and COPD}

There are increased implications related to nicotinic receptor anticholinergic system and ACE 2 inhibitors that they increase the ACE 2 receptor expression in bronchial epithelial cells [18]. Nicotine up-regulates ACE-2 through alpha7 nAChRs which are present in neuronal and non-neuronal cells [19]. But the nAChR relationship is still controversial and needs to be explored. Epithelial cell expression of CHRNA7 which encodes Alpha 7-nicotinic Acetylcholine receptor is correlated with increased gene expression of ACE. There was a positive pearson correlation between ACE expression and $\mathrm{nAch}$. There is an increased expression of CHRNA7 expression in COPD patients and current smokers indicating a positive progression of the disease. It was also inversely correlated with FEV1 percentage in COPD patients [20].

\subsection{Mortality/Morbidity}

According to Salah, H.M., T. Sharma, and J. Mehta's Meta-Analysis, which included ten studies with a total of 11,189 patients, mortality was found to be $29.4 \%$ among smokers in comparison to $17.0 \%$ in non-smokers. RR was found 
to be 2.07 (95\% CI: 1.59, 2.69). But mortality risk in current and former smokers was found to have no difference (RR: 1.03; 95\% CI: 0.75, 1.40) based on analysis in four studies with 532 patients [21]. This analysis shows, in patients with COVID-19 smoking is associated with significantly higher risk of mortality.

\subsection{Nicotine as a Protective Agent}

Efficient viral invasion and replication can generate an aggressive hyper inflammatory immune response with release of large number of proinflammatory cytokines which is clinically known as cytokine storm [22]. It is characterized by overwhelming systemic inflammation, hyperferritinemia, dysfunction of hemodynamics and multiorgan dysfunction which can lead to death [23]. This cytokine storm is one of the common causes of death in COVID-19. Therapeutic management of Cytokine storm can reduce mortality and morbidity in COVID-19. One of the mechanisms by which body tackles proinflammatory signals is through Nicotinic Acetylcholinergic System (NAS). Generally, NAS inhibits proinflammatory cytokine production by inhibiting NF-KB pathways [24]. Alexandris et al. showed protective effect of nicotine in COVID-19 by simulating cholinergic anti-inflammatory pathways [25]. According to their study, nicotine prevents with SARS-CoV-2 S1 protein to bind with nAch Recpetors for their entry. Further, Nicotine prevents proinflammatory effects of virus through NAS anti-inflammatory pathways.

\section{Methodology}

\section{Search Method and Strategy}

An extensive literature review was conducted of databases PubMed, Google Scholar, Cochrane using keywords like "COVID-19", "SARS-CoV-2", "novel coronavirus", "smoking", "smokers", "nicotine" from December 2019 through $30^{\text {th }}$ October 2020. English articles related to the epidemiology of COVID-19 in adult smokers, including systematic reviews, meta-analysis, prospective and retrospective cohort studies, cross-sectional studies, case series, and case reports based on the relevance of titles and abstracts to the topic were included. The search was comprehensive with cross-checking of reference lists from the articles retrieved. In doing so, we had 33 articles for the final review. Our review included studies from various countries from across the globe. Referencing was done according to guidelines using EndNote.

\section{Ethical Approval and Funding}

This study did not require ethical approval as data was obtained from already available databases, and patients were not directly involved. No funding was obtained for this review.

\section{Results}

Our search results lead to 54 studies and after removing duplicates. We also 
performed the manual search to look for related articles. 33 studies were included in the final analysis.

Smokers were 1.4 times more likely to have severe COVID-19 $(\mathrm{RR}=1.495 \%$ CI: $0.98-2.00)$, and 2.4 times more likely to require an ICU admission $(\mathrm{RR}=2.4$ CI: 1.43 - 4.04) when compared to non-smokers ( $\mathrm{n}=926)$.

Smoking enhances the activity of ACE 2 receptor and TMPRSS2 inhibitor and hence helps in the facilitation of viral entry and activation.

Over the course of the disease, nicotine eventually leads to a cytokine storm by the release of IL-6, TNF- $\alpha$, IFN- $\gamma$, IL-2, IL-7, IP-10, MCP-3 or GM-CSF and other inflammatory mediators. The reduction in serine protease inhibition can lead to the cleavage of the S1/S2 site by furin and thereby enhance the cell to cell transmission.

Current smokers were less likely to experience an adverse outcome (OR: 0.42, $95 \%$ CI: 0.24 - 0.74), compared to former smokers. $22 \%$ of current smokers and $46 \%$ of former smokers had more severe complications compared to non-smokers with COVID-19 infection. Current smokers had a case fatality rate of $38.5 \%(\mathrm{n}=$ 1790). They had higher odds of mortality compared to non-smokers ( $\mathrm{OR}=1.25)$, especially males $>65$ years $(\mathrm{OR}=2.51)$. Tobacco smoke upregulates inflammatory cytokines like TNF- $\alpha$, IL- $1 \beta$, and neutrophils by activating NF-k. This leads to increased epithelial cell permeability, mucus production, and impaired mucociliary clearance.

\section{Discussion}

Our analysis clearly demonstrates smoking as a risk factor for severe COVID-19 infection. Myriads of pathophysiological processes like pulmonary epithelial cell permeability, mucus production, and impaired mucociliary clearance due to increased inflammatory cytokine production are well linked to nicotine smoking [9]. This kind of predisposition could be one of many other reasons that smokers (active) are highly susceptible severe form of COVID-19 infection (Figures 3-5).

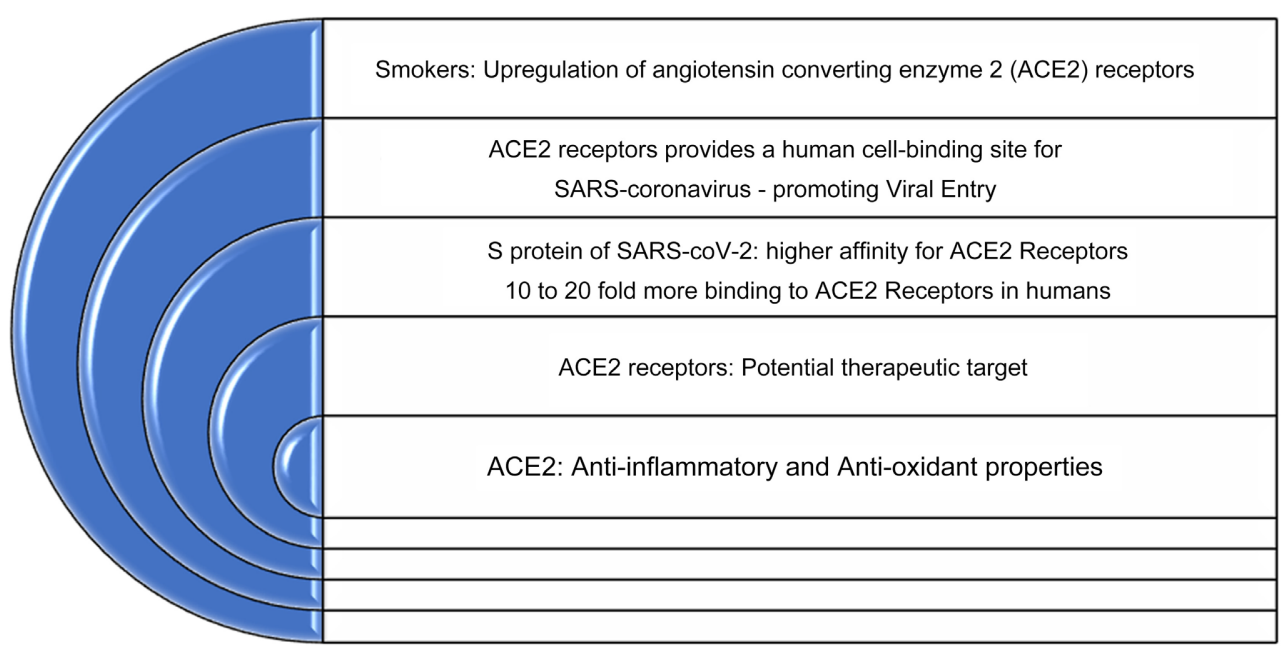

Figure 3. Receptors common in smoking and COVID-19 ([17] [26] [27] [28]). 


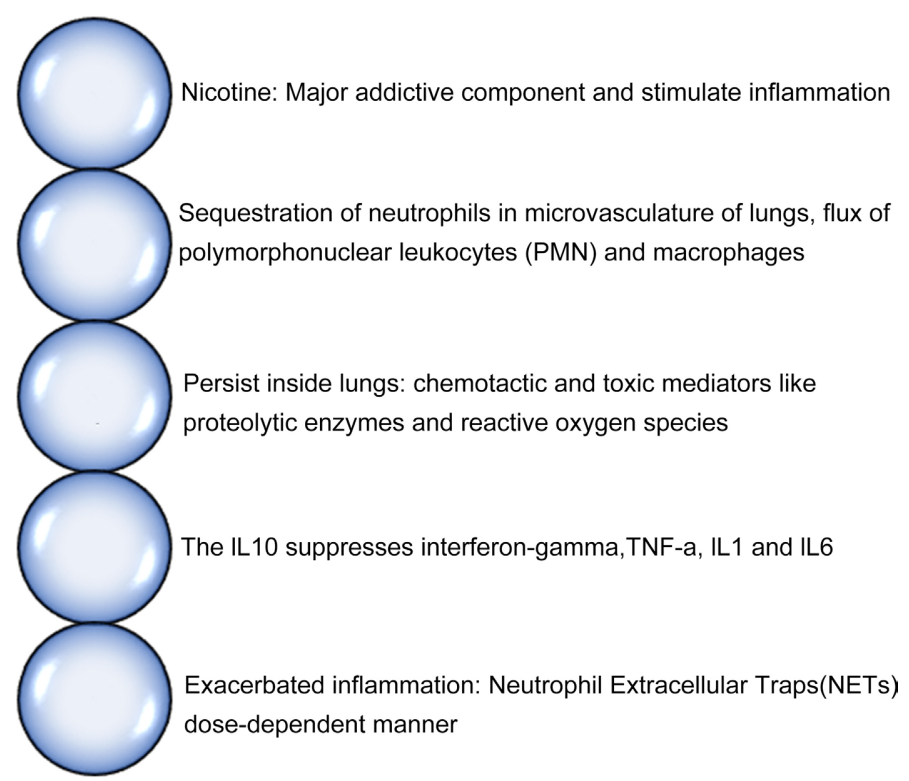

Figure 4. Tobacco smoke as an inflammatory agent ([29]-[36]).

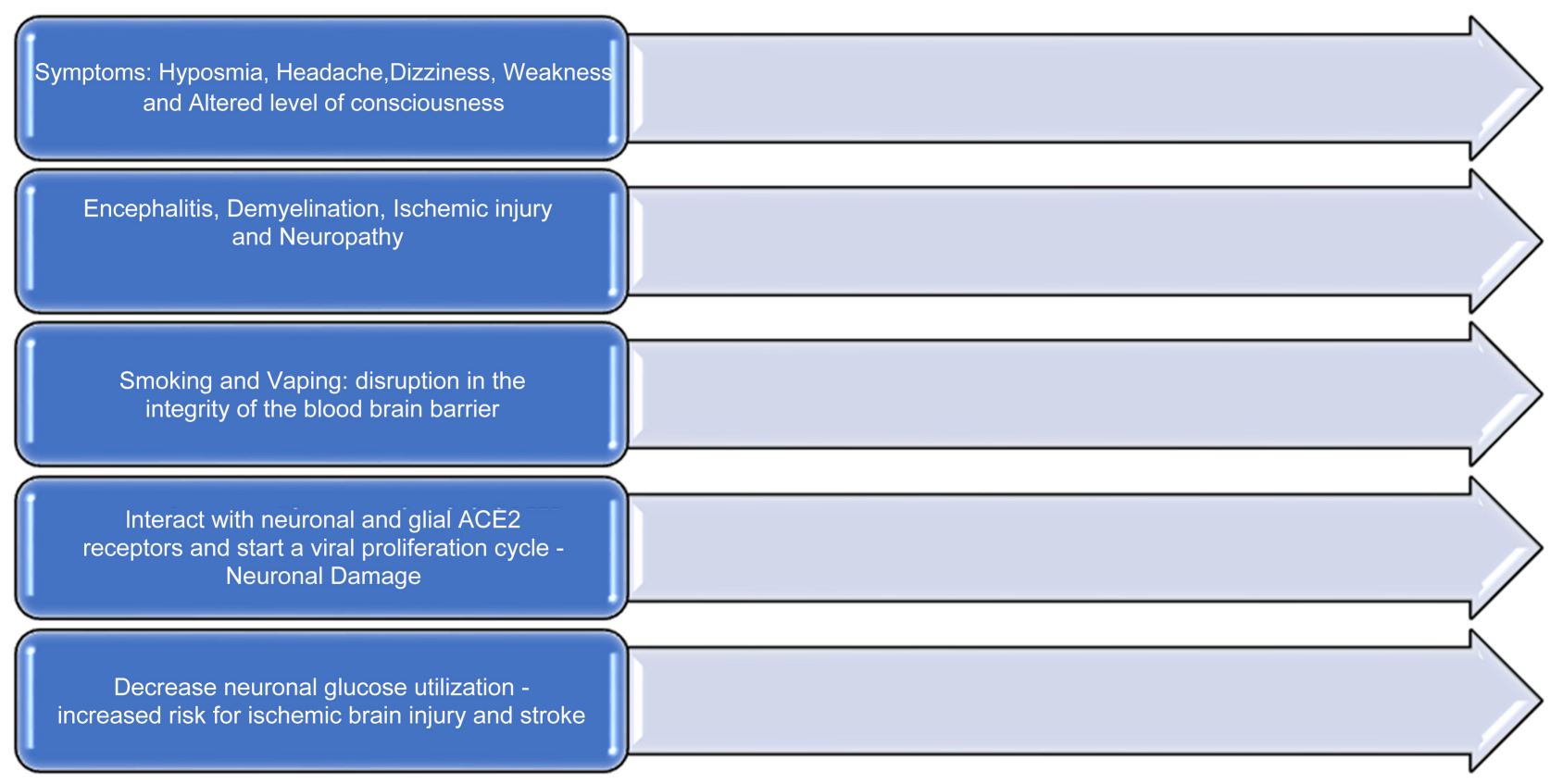

Figure 5. Neurological risks ([4], [37]-[42]).

As the COVID-19 pandemic still continues to be a major health threat in the world today, any strategies that could reduce the rate of infection or help in flattening the curve of the virus transmission should be adopted without any delay. Hence, with the evidence provided by our study that smoking tobacco increases the risk of COVID-19 infection, we should consider smoking cessation as an essential step to reduce COVID-19 infection.

Authors conclude that smoking cessation can drastically reduce risk of virus exposure by decreasing the hand to mouth action. Additionally, smoking cessa- 
tion decreases the pathological proinflammatory impact of nicotine in pulmonary vasculature that helps viral entry though the respiratory tract.

\section{Conclusion}

Smoking is associated with worse outcomes and mortality in COVID-19. Smoking is found to be one of the high-risk factors related to the severity and complications of COVID-19. Nicotine accumulated by smoking impairs lung function, and hence makes the lung susceptible to severe respiratory infections. There is a need for further studies to gather evidence on the effects of second-hand smoke on the effects of SARS-CoV-2 infection. But, it can be well assumed that smokers may have a serious risk of succumbing to SARS-CoV-2 infection. Abstinence or cessation of smoking helps to recover ciliary clearance of the airway and immune function as early as 30 days. Thus, smoking cessation awareness campaigns are strongly recommended as part of public health measures to curb the global impact of COVID-19. Public education about smoking cessation should be implemented along with standard guidelines to prevent disease progression in this susceptible population.

\section{Conflicts of Interest}

There is no conflict of interest from all authors.

\section{References}

[1] Kaur, G., Lungarella, G. and Rahman, I. (2020) SARS-CoV-2 COVID-19 Susceptibility and Lung Inflammatory Storm by Smoking and Vaping. Journal of Inflammation, 17, Article No. 21. https://doi.org/10.1186/s12950-020-00250-8

[2] Alqahtani, J.S., Oyelade, T., Aldhahir, A.M., Alghamdi, S.M., Almehmadi, M., Alqahtani, A.S., et al. (2020) Prevalence, Severity and Mortality Associated with COPD and Smoking in Patients with COVID-19: A Rapid Systematic Review and Meta-Analysis. PLoS ONE, 15, e0233147. https://doi.org/10.1371/journal.pone.0233147

[3] Lang, A.E. and Yakhkind, A. (2020) Coronavirus Disease 2019 and Smoking: How and Why We Implemented a Tobacco Treatment Campaign. Chest, 158, 1770-1776. https://doi.org/10.1016/j.chest.2020.06.013

[4] Archie, S.R. and Cucullo, L. (2020) Cerebrovascular and Neurological Dysfunction under the Threat of COVID-19: Is There a Comorbid Role for Smoking and Vaping? International Journal of Molecular Sciences, 21, Article No. 3916. https://doi.org/10.3390/ijms21113916

[5] Farsalinos, K., Barbouni, A., Poulas, K., Polosa, R., Caponnetto, P. and Niaura, R. (2020) Current Smoking, Former Smoking, and Adverse Outcome among Hospitalized COVID-19 Patients: A Systematic Review and Meta-Analysis. Therapeutic Advances in Chronic Disease, 11, Article ID: 2040622320935765. https://doi.org/10.1177\%2F2040622320935765

[6] Zheng, Z., Peng, F., Xu, B., Zhao, J., Liu, H., Peng, J., et al. (2020) Risk Factors of Critical \& Mortal COVID-19 Cases: A Systematic Literature Review and Meta-Analysis. Journal of Infection, 81, e16-e25. https://doi.org/10.1016/j.jinf.2020.04.021

[7] Emami, A., Javanmardi, F., Pirbonyeh, N. and Akbari, A. (2020) Prevalence of Underlying Diseases in Hospitalized Patients with COVID-19: A Systematic Review 
and Meta-Analysis. Archives of Academic Emergency Medicine, 24, Article No. e35. https://pubmed.ncbi.nlm.nih.gov/32232218/

[8] van Zyl-Smit, R.N., Richards, G. and Leone, F.T. (2020) Tobacco Smoking and COVID19 Infection. The Lancet Respiratory Medicine, 8, 664-665.

https://doi.org/10.1016/s2213-2600(20)30239-3

[9] Hopkinson, N.S., Rossi, N., El-Sayed, M.J., Laverty, A.A., Quint, J.K., Freidin, M., et al. (2021) Current Smoking and COVID-19 Risk: Results from a Population Symptom App in over 2.4 Million People. Thorax, 76, 714-722. http://doi.org/10.1136/thoraxjnl-2020-216422

[10] Jackson, S.E., Brown, J., Shahab, L., Steptoe, A. and Fancourt, D. (2020) COVID-19, Smoking and Inequalities: A Study of 53002 Adults in the UK. Tobacco Control, 1, Article ID: tobaccocontrol-2020-055933.

[11] Umnuaypornlert, A., Kanchanasurakit, S., Lucero-Prisno, D.E.I. and Saokaew, S. (2021) Smoking and Risk of Negative Outcomes among COVID-19 Patients: A Systematic Review and Meta-Analysis. Tobacco Induced Diseases, 19, Article No. 9. https://doi.org/10.18332/tid/132411

[12] Wang, Y., Xu, J., Meng, Y., Adcock, I.M. and Yao, X. (2018) Role of Inflammatory Cells in Airway Remodeling in COPD. International Journal of Chronic Obstructive Pulmonary Disease, 13, 3341-3348. https://doi.org/10.2147/COPD.S176122

[13] McGuinness, A.J. and Sapey, E. (2017) Oxidative Stress in COPD: Sources, Markers, and Potential Mechanisms. Journal of Clinical Medicine, 6, Article No. 21. https://doi.org/10.3390/jcm6020021

[14] Hikichi, M., Mizumura, K., Maruoka, S. and Gon, Y. (2019) Pathogenesis of Chronic Obstructive Pulmonary Disease (COPD) Induced by Cigarette Smoke. Journal of Thoracic Disease, 11, S2129-S2140. https://doi.org/10.21037/jtd.2019.10.43

[15] Wang, D., Hu, B., Hu, C., Zhu, F., Liu, X., Zhang, J., et al. (2020) Clinical Characteristics of 138 Hospitalized Patients with 2019 Novel Coronavirus-Infected Pneumonia in Wuhan, China. The Journal of the American Medical Association, 323, 1061 1069. https://doi.org/10.1001/jama.2020.1585

[16] Graham, B.L., Steenbruggen, I., Miller, M.R., Barjaktarevic, I.Z., Cooper, B.G., Hall, G.L., et al. (2019) Standardization of Spirometry 2019 Update. An Official American Thoracic Society and European Respiratory Society Technical Statement. American Journal of Respiratory and Critical Care Medicine, 200, e70-e88. https://doi.org/10.1164/rccm.201908-1590st

[17] Leung, J.M., Yang, C.X., Tam, A., Shaipanich, T., Hackett, T.-L., Singhera, G.K., et al. (2020) ACE-2 Expression in the Small Airway Epithelia of Smokers and COPD Patients: Implications for COVID-19. European Respiratory Journal, 55, Article ID: 2000688. https://doi.org/10.1183/13993003.00688-2020

[18] Russo, P., Bonassi, S., Giacconi, R., Malavolta, M., Tomino, C. and Maggi, F. (2020) COVID-19 and Smoking: Is Nicotine the Hidden Link? European Respiratory Journal, 55, Article ID: 2001116. https://doi.org/10.1183/13993003.01116-2020

[19] Farsalinos, K., Angelopoulou, A., Alexandris, N. and Poulas, K. (2020) COVID-19 and the Nicotinic Cholinergic System. European Respiratory Journal, 56, Article ID: 2001589. https://doi.org/10.1183/13993003.01589-2020

[20] Leung, J.M., Yang, C.X. and Sin, D.D. (2020) COVID-19 and Nicotine as a Mediator of ACE-2. European Respiratory Journal, 55, Article ID: 2001261. https://doi.org/10.1183/13993003.01261-2020

[21] Salah, H.M., Sharma, T. and Mehta, J. (2020) Smoking Doubles the Mortality Risk 
in COVID-19: A Meta Analysis of Recent Reports and Potential Mechanisms. $\mathrm{Cu}$ reus, 12, Article ID: e10837. https://doi.org/10.7759/cureus.10837

[22] Zhang, C., Zhao, W., Li, J.-W., Zhao, H. and Wang, G.-Q. (2020) The Cytokine Release Syndrome (CRS) in Severe COVID-19: Interleukin-6 Receptor Antagonist Tocilizumab May Be the Key to Reduce Mortality. International Journal of Antimicrobial Agents, 55, Article ID: 105954.

https://doi.org/10.1016/j.ijantimicag.2020.105954

[23] Shimizu, M. (2019) Clinical Features of Cytokine Storm Syndrome. In: Cron, R.Q. and Behrens, E.M., Eds., Cytokine Storm Syndrome, Springer International Publishing, Cham, 31-41. https://doi.org/10.1007/978-3-030-22094-5 3

[24] Saeed, R.W., Varma, S., Peng-Nemeroff, T., Sherry, B., Balakhaneh, D., Huston, J., et al. (2005) Cholinergic Stimulation Blocks Endothelial Cell Activation and Leukocyte Recruitment during Inflammation. The Journal of Experimental Medicine, 201, 1113-1123. https://doi.org/10.1084/jem.20040463

[25] Alexandris, N., Lagoumintzis, G., Chasapis, C.T., Leonidas, D.D., Papadopoulos, G.E., et al. (2021) Nicotinic Cholinergic System and COVID-19: In Silico Evaluation of Nicotinic Acetylcholine Receptor Agonists as Potential Therapeutic Interventions. Toxicology Reports, 8, 73-83. https://doi.org/10.1016/j.toxrep.2020.12.013

[26] Li, W., Moore, M.J., Vasilieva, N., Sui, J., Wong, S.K., et al. (2003) Angiotensin-Converting Enzyme 2 Is a Functional Receptor for the SARS Coronavirus. Nature, 426, 450-454. https://doi.org/10.1038/nature02145

[27] Farsalinos, K., Barbouni, A. and Niaura, R. (2020) Systematic Review of the Prevalence of Current Smoking among Hospitalized COVID-19 Patients in China: Could Nicotine Be a Therapeutic Option? Internal and Emergency Medicine, 15, 845-852. https://doi.org/10.1007/s11739-020-02355-7

[28] Wrapp, D., Wang, N., Corbett, K.S., Goldsmith, J.A., Hsieh, C.-L., Abiona, O., et al. (2020) Cryo-EM Structure of the 2019-nCoV Spike in the Prefusion Conformation. Science, 367, 1260-1263. https://doi.org/10.1126/science.abb2507

[29] Roth, M.D., Arora, A., Barsky, S.H., Kleerup, E.C., Simmons, M. and Tashkin, D.P. (1998) Airway Inflammation in Young Marijuana and Tobacco Smokers. American Journal of Respiratory and Critical Care Medicine, 157, 928-937. https://doi.org/10.1164/ajrccm.157.3.9701026

[30] Tsujii, M., Iijima, H., Nishida, T. and Takehara, T. (2013) Smoking and Alimentary Diseases. Nihon Rinsho (Japanese Journal of Clinical Medicine), 71, 436-442.

[31] Rouse, R.L., Boudreaux, M.J. and Penn, A.L. (2007) In Utero Environmental Tobacco Smoke Exposure Alters Gene Expression in Lungs of Adult BALB/c Mice. Environmental Health Perspectives, 115, 1757-1766. https://doi.org/10.1289/ehp.10358

[32] Takubo, Y., Guerassimov, A., Ghezzo, H., Triantafillopoulos, A., Bates, J.H.T., Hoidal, J.R., et al. (2002) $\alpha_{1}$-Antitrypsin Determines the Pattern of Emphysema and Function in Tobacco Smoke-Exposed Mice: Parallels with Human Disease. American Journal of Respiratory and Critical Care Medicine, 166, 1596-1603. https://doi.org/10.1164/rccm.2202001

[33] Churg, A., Wang, R.D., Tai, H., Wang, X., Xie, C., Dai, J., et al. (2003) Macrophage Metalloelastase Mediates Acute Cigarette Smoke-Induced Inflammation via Tumor Necrosis Factor-a Release. American Journal of Respiratory and Critical Care Medicine, 167, 1083-1089. https://doi.org/10.1164/rccm.200212-1396OC

[34] Fiorentino, D.F., Zlotnik, A., Mosmann, T.R., Howard, M. and O’Garra, A. (1991) IL-10 Inhibits Cytokine Production by Activated Macrophages. The Journal of Immunology, 147, 3815-3822.

[35] Hosseinzadeh, A., Thompson, P.R., Segal, B.H. and Urban, C.F. (2016) Nicotine In- 
duces Neutrophil Extracellular Traps. Journal of Leukocyte Biology, 100, 1105-1112. https://doi.org/10.1189/jlb.3AB0815-379RR

[36] Brinkmann, V., Reichard, U., Goosmann, C., Fauler, B., Uhlemann, Y., Weiss, D.S., et al. (2004) Neutrophil Extracellular Traps Kill Bacteria. Science, 303, 1532-1535. https://doi.org/10.1126/science.1092385

[37] Montalvan, V., Lee, J., Bueso, T., De Toledo, J. and Rivas, K. (2020) Neurological Manifestations of COVID-19 and Other Coronavirus Infections: A Systematic Review. Clinical Neurology and Neurosurgery, 194, Article ID: 105921.

https://doi.org/10.1016/j.clineuro.2020.105921

[38] Klein, R.S., Garber, C. and Howard, N. (2017) Infectious Immunity in the Central Nervous System and Brain Function. Nature Immunology, 18, 132-141. https://doi.org/10.1038/ni.3656

[39] Sajja, R.K., Naik, P. and Cucullo, L. (2015) Differential Cerebrovascular Toxicity of Various Tobacco Products: A Regulatory Perspective. Journal of Pharmacovigilance, 3, Article No. e130. https://doi.org/10.4172/2329-6887.1000e130

[40] Kaisar, M.A., Villalba, H., Prasad, S., Liles, T., Sifat, A.E., Sajja, R.K., et al. (2017) Offsetting the Impact of Smoking and E-Cigarette Vaping on the Cerebrovascular System and Stroke Injury: Is Metformin a Viable Countermeasure? Redox Biology, 13, 353-362. https://doi.org/10.1016/j.redox.2017.06.006

[41] Sifat, A.E., Vaidya, B., Kaisar, M.A., Cucullo, L. and Abbruscato, T.J. (2018) Nicotine and Electronic Cigarette (E-Cig) Exposure Decreases Brain Glucose Utilization in Ischemic Stroke. Journal of Neurochemistry, 147, 204-221. https://doi.org/10.1111/jnc.14561

[42] Mao, L., Wang, M., Chen, S., He, Q., Chang, J., Hong, C., Zhou, Y., Wang, D., Jin, H. and Hu, B. (2020) Neurological Manifestations of Hospitalized Patients with COVID-19 in Wuhan, China: A Retrospective Case Series Study. medRxiv. https://doi.org/10.1101/2020.02.22.20026500 